\title{
Publicidad de terapias innovadoras
}

\section{Advertising of innovative therapies}

$\mathrm{C}^{\mathrm{o}}$ on relativa periodicidad tomamos conocimiento de que una nueva droga, terapia o procedimiento permitiría mejorar o curar una o varias de las tantas enfermedades serias y devastadoras con las cuales nos enfrentamos en el ejercicio diario de nuestras especialidades. Muchas veces nos enteramos de estos supuestos adelantos a través de publicaciones en medios masivos y no científicos de difusión o también por la comunicación directa de nuestros propios pacientes o familiares. Precisamente, por estos días y a modo de ejemplo, leímos con asombro la noticia referida a una clínica privada donde de manera textual se afirmaba que "ya se puede detener el avance del Parkinson y el Alzheimer en Chile. Utilizando las células madre directo en el cerebro, este tratamiento probado clínicamente, permite detener los avances de estas patologías y obtener mejorías evidentes en los pacientes. A través de un procedimiento mínimamente invasivo se aplican células madre directamente al Polígono de Willis. Es un procedimiento que no tiene mayores riesgos". Con curiosidad, profundizamos nuestra indagación acerca de la oferta terapéutica de este centro y nos encontramos con que, entre muchas otras enfermedades que serían objeto de esta medicina regenerativa, también se encontraban las secuelas del accidente cerebrovascular, la distrofia muscular, la esclerosis lateral amiotrófica y la esclerosis múltiple.

Obviando lo temerario de la sentencia anterior y específicamente con respecto a células madre, podemos señalar que el potencial uso de estas células o sus derivados en biomedicina ha implicado en las últimas dos décadas gran expectativa en el público general y en la comunidad científica. Sin embargo, y esto es lo importante, a pesar de profusas campa- ñas comerciales creadas por una industria no bien regulada, el hecho cierto es que aún no hay evidencia científica de eficacia y seguridad en la administración de células madre embrionarias o adultas, a lo menos, en las enfermedades neurológicas.

Pensamos que este tipo de anuncios genera dos problemas graves. Primero y desde una perspectiva bioética, produce una falsa ilusión entre pacientes y familiares desesperados por encontrar una cura para su enfermedad y luego, desprestigia una línea legítima de investigación y desarrollo que debe transitar, como toda investigación científica que pretende encontrar una alternativa para prevenir o curar, un largo, sistemático, costoso y complejo proceso que suele incluir modelos animales y varias fases en seres humanos. Mientras estas terapias no sean comunicadas formalmente en publicaciones biomédicas serias o no cuenten con la autorización de los organismos reguladores correspondientes, su utilización constituirá una praxis seudocientífica.

Para resolver la dificultad originada en la desinformación de la población acerca de estas ofertas de tratamientos sin sustento claro, se han creado comités internacionales de expertos encargados de diseñar guías de información destinadas a pacientes, familiares y profesionales. Creemos que las sociedades científicas constituyen voz autorizada para alertar oportunamente a la comunidad y también a nuestros propios pares acerca de los mitos y realidades de estos innovadores tratamientos, difundiendo de manera amplia el material científico más objetivo y veraz disponible. Nuestro silencio ante esta dudosa y presuntuosa oferta agrava el desamparo en que se encuentran muchos de nuestros pacientes afectados por enfermedades todavía incurables.

Dr. Patricio Fuentes G. Editor 